\title{
Limbic Thalamic Lesions, Appetitively Motivated Discrimination Learning, and Training-Induced Neuronal Activity in Rabbits
}

\author{
David M. Smith, ${ }^{1,2}$ John H. Freeman Jr, ${ }^{4}$ Daniel Nicholson, ${ }^{4}$ and Michael Gabriel ${ }^{1,2,3}$ \\ ${ }^{1}$ Neuroscience Program, ${ }^{2}$ Beckman Institute Neuronal Pattern Analysis Group, and ${ }^{3}$ Department of Psychology, \\ University of Illinois, Urbana, Illinois 61801, and " Department of Psychology, University of lowa, lowa City, lowa 52242
}

\begin{abstract}
A substantial literature implicates the anterior and mediodorsal (limbic) thalamic nuclei and the reciprocally interconnected areas of cingulate cortex in learning, memory, and attentional processes. Previous studies have shown that limbic thalamic lesions severely impair discriminative avoidance learning and that they block development of training-induced neuronal activity in the cingulate cortex. The present study investigated the possibility that the limbic thalamus and cingulate cortex are involved in reward-based discriminative approach learning, wherein head-extension responses yielding oral contact with a drinking spout that was inserted into the conditioning chamber after a positive conditional stimulus (CS+) were reinforced with a water reward but responses to the spout after a negative conditional stimulus (CS-) were not reinforced. In this task, the rabbits learned primarily to omit their prepotent responses to the spout on CS- trials. Acquisition was severely impaired in
\end{abstract}

rabbits given limbic thalamic lesions before training. As during avoidance learning, posterior cingulate cortical neurons of control rabbits developed learning-related neuronal responses to task-relevant stimuli, but this activity was severely attenuated in rabbits with lesions. These results support a general involvement of the cingulothalamic circuitry in instrumental approach and avoidance learning. The fact that learning consisted of response omission indicated that the cingulothalamic role is not limited to acquisition or production of active behavioral responses, such as locomotion. It is proposed that cingulothalamic neurons mediate associative attention, wherein enhanced neuronal responses to stimuli associated with reinforcement facilitate the selection and production of task-relevant responses.

Key words: cingulate cortex; discrimination; approach; limbic thalamus; learning; attention; neuronal activity
A substantial experimental literature implicates the anterior and mediodorsal (MD) "limbic" nuclei of the thalamus and their interconnected cingulate cortical projection fields in processes of learning, memory, and attention (Victor et al., 1971; Isserhoff et al., 1982; Markowitsch, 1982; Beracochea et al., 1989; Squire et al., 1989; Bussey et al., 1996, 1997; Parker and Gaffan, 1997; Posner and DiGirolamo, 1998; Aggleton and Brown, 1999). Included in the array of learning situations subserved by these cingulothalamic areas is discriminative instrumental avoidance learning, wherein rabbits learn to locomote in a wheel apparatus to avoid a shock in response to a tone [positive conditional stimulus $(\mathrm{CS}+)]$ and they learn to ignore a different tone [negative conditional stimulus $(\mathrm{CS}-)]$ that is not followed by shock. Cingulothalamic neurons exhibit training-induced neuronal activity (TIA), insofar as they become more responsive, at brief latencies, to the $\mathrm{CS}+$ than to the $\mathrm{CS}-$ during training (for review, see Gabriel, 1993). Lesions of the limbic thalamus blocked avoidance learning and abolished training-induced neuronal activity in the cingulate cortex (Gabriel et al., 1989).

Although these results indicate an important involvement of the cingulothalamic circuitry in discriminative avoidance learning, precise specification of the cingulothalamic contribution has

\footnotetext{
Received Feb. 4, 2002; revised June 7, 2002; accepted June 10, 2002.
}

This work was supported by National Institutes of Health Grant NS36591, National Institute of Mental Health (NIMH) Grant MH58259, National Institute on Drug Abuse Grant DA11164, National Science Foundation Grant BIR95-04842 (M.G.), and NIMH Grant F31-MH12077 (D.S.).

Correspondence should be addressed to Dr. Michael Gabriel, University of Illinois, Beckman Institute, 405 North Mathews, Urbana, IL 61801. E-mail: mgabriel@s.psych.uiuc.edu.

Copyright (C) 2002 Society for Neuroscience $\quad 0270-6474 / 02 / 228212-10 \$ 15.00 / 0$ not yet been achieved. For example, cingulothalamic involvement may be limited to aversively motivated instrumental learning or to the production of particular classes of instrumental behavior, such as locomotion. Because the avoidance learning deficit was evidenced by a failure to produce avoidance responses to the $\mathrm{CS}+$, it is possible that the lesions disrupted the ability to initiate locomotor responses on cue.

To address these issues, an instrumental discriminative approach task was implemented wherein water reward is earned by head extension and oral contact with a water spout that is inserted into the experimental chamber after the $\mathrm{CS}+$. No reward is given for spout contact responses made after the $\mathrm{CS}-$. In a previous study, cingulothalamic neurons exhibited training-induced activity similar to the activity seen during discriminative avoidance learning, suggesting common functions of these neurons in instrumental approach and avoidance learning (Freeman et al., 1996). The present study was performed to determine whether limbic thalamic lesions would impair approach learning and disrupt cingulate cortical neuronal responses, as has been shown for discriminative avoidance learning. A positive outcome would implicate the cingulothalamic circuitry in a general associative function rather than a function specific to the avoidance learning task.

\section{MATERIALS AND METHODS}

Subjects and surgical procedures. The subjects were 28 male New Zealand White rabbits (Myrtle's Rabbitry, Thompson Station, TN). Seven days after arrival in the Beckman Institute vivarium, the rabbits were placed on a moderately restricted diet (one cup of Purina rabbit chow daily) to control obesity. After 1-2 weeks for recovery from surgery, the rabbits 
were placed on a restricted regimen of $100 \mathrm{ml}$ of water daily. They were given at least 1 week to adjust to this regimen before training.

Bilateral electrolytic lesions of the anterior and mediodorsal thalamic nuclei were induced in 15 rabbits. The electrodes used for making the lesions were stainless steel insect pins insulated with Epoxylite, with $0.80-0.90 \mathrm{~mm}$ of the insulation removed from the tip. Four bilateral sites were chosen for the lesions to produce maximal damage in the target nuclei. The coordinates chosen resulted in four lesions: one each in the anterior and posterior regions of the anterior nuclear complex, one in the anterodorsal region of the MD nucleus, and one in the posteroventral MD thalamic nucleus. The stereotaxic coordinates (Girgis and ShihChang, 1981) and durations of current passage were as follows: (1) anteroposterior (AP), $1.5 \mathrm{~mm}$ posterior to bregma; mediolateral (ML), $2.3 \mathrm{~mm}$; dorsoventral (DV), $8.4 \mathrm{~mm}$; $35 \mathrm{sec}$; (2) AP, $2.5 \mathrm{~mm}$; ML, $2.3 \mathrm{~mm}$; DV, $8.1 \mathrm{~mm}$; $40 \mathrm{sec}$; (3) AP, $3.5 \mathrm{~mm}$; ML, $1.4 \mathrm{~mm}$; DV, $8.7 \mathrm{~mm} ; 35 \mathrm{sec}$; and (4) AP, $4.5 \mathrm{~mm}$; ML, $1.6 \mathrm{~mm}$; DV, $9.2 \mathrm{~mm}$; $55 \mathrm{sec}$.

During surgery, six fixed-position stainless steel microelectrodes were implanted intracranially in all rabbits for the recording of neuronal (multiple-unit) activity during training. Details of electrode fabrication and implantation were given previously (Gabriel et al., 1995). The target sites for recording electrodes were as follows: (1) anterior cingulate cortex, AP, $3.5 \mathrm{~mm}$ anterior to bregma; ML, $0.8 \mathrm{~mm}$; DV, $3.5 \mathrm{~mm}$; (2) posterior cingulate cortex, AP, $4.0 \mathrm{~mm}$ posterior to bregma; $\mathrm{ML}, 0.8 \mathrm{~mm}$; DV, $1.5 \mathrm{~mm}$; (3) the basolateral (BL) nucleus of the amygdala, AP, 0.5 $\mathrm{mm}$ posterior to bregma; ML, $5.5 \mathrm{~mm}$; DV, $13.25 \mathrm{~mm}$; and (4) the medial division of the medial geniculate (MG) nucleus, AP, $7.5 \mathrm{~mm}$ posterior to bregma; ML, $5.0 \mathrm{~mm}$; DV, $9.0 \mathrm{~mm}$. Control rabbits underwent surgical procedures similar to rabbits with lesions but had recording electrodes implanted in the MD thalamic nucleus (AP, $4.6 \mathrm{~mm}$ posterior to bregma; ML, $1.5 \mathrm{~mm}$; DV, $8.0 \mathrm{~mm}$ ) and the anteroventral (AV) thalamic nucleus (AP, $2.0 \mathrm{~mm}$ posterior to bregma; ML, $2.3 \mathrm{~mm}$; DV, $7 \mathrm{~mm}$ ) in addition to the other sites. Because insufficient data were obtained from the amygdalar and thalamic sites, only the behavioral data and cingulate cortical neuronal data are reported here.

Discriminative approach training. The rabbits were given daily training sessions in an apparatus designed for the administration of discriminative approach training. The instrumental response was head extension and oral contact with a drinking spout. The experiment was conducted while the rabbits occupied a cubical chamber that provided electrical shielding and sound attenuation. Within the chamber, rabbits occupied a Plexiglas rabbit restrainer that allowed free head movement. Two pure tones ( 1 or $8 \mathrm{kHz}$; duration, $500 \mathrm{msec}$; $85 \mathrm{~dB}$ at $20 \mu \mathrm{N} / \mathrm{m}^{2}$; rise time, 3 msec) were assigned in a counterbalanced manner as the CS+ and the $\mathrm{CS}-$. During training, the onset of the CS + was followed after $4 \mathrm{sec}$ by insertion of a drinking spout through an opening in the chamber wall. Head extension of $\sim 4 \mathrm{~cm}$ was required for the rabbits to reach the spout. Water reward $(3 \mathrm{ml}$ in $2 \mathrm{sec}$ ) was delivered during oral contact with the spout. Spout contact responses were detected by a grounding circuit. CS - presentation was also followed by spout presentation and spout contact responses were recorded, but no reward was delivered. Instead, spout contact responses were followed immediately by retraction of the spout.

Acclimation and preliminary training. Before training, rabbits were given daily sessions for acclimation to the conditioning chamber and spout presentations. In these sessions, 60 spout presentations were given at irregular intervals until the rabbits reached a criterion of at least 45 spout contact responses in a session. After acclimation, the rabbits received two preliminary training sessions during which baseline neuronal data were recorded for comparison with later training sessions. In the first preliminary training session, the tones to be used as conditional stimuli were presented 60 times each in an irregular sequence without spout presentation or water reward. In the second session, the tone conditional stimuli were presented 60 times each with the water spout presented in an explicitly unpaired manner. The rabbits could obtain water reward for spout contact responses. After preliminary training, the rabbits received daily training sessions consisting of 120 trials (60 trials each with the CS+ and CS-, presented in an irregular sequence). The intertrial interval was $8,13,18,23$, or $28 \mathrm{sec}$, with these values occurring in an irregular order. Training continued until the rabbits reached a criterion in which the percentage of spout contact responses on $\mathrm{CS}+$ trials exceeded the percentage of spout contact responses on CS - trials by at least $50 \%$. This discriminative performance had to be achieved in two consecutive training sessions. On the last day of training before they were killed, all rabbits were given access to water ad libitum for $15 \mathrm{~min}$ in the training apparatus to assess possible motivational effects of lesions.
Brief-latency CS-elicited neuronal responses. The neuronal signals were fed from each electrode to field-effect transistors (FETs) that served as high-impedance source followers. The FETs were affixed to a connector that mated with a connector affixed to the rabbit's skull. This arrangement minimized the length of the conduction pathway $(\sim 2.5 \mathrm{~cm})$ from the recording sites to the first stage of signal amplification. The FET outputs were fed to a preamplifier appropriate for unit recording (gain of 40,000; half-amplitude cutoffs at 500 and $8000 \mathrm{~Hz}$ ). The records were subjected to a second stage of active bandpass filtering (half-amplitude cutoffs at 600 and $8000 \mathrm{~Hz}$; roll-off at $18 \mathrm{~dB} /$ octave). The records were then fed to Schmitt triggers with thresholds set on each channel to allow triggering at a mean rate of 110-190 spikes per second. With these settings, several of the larger spikes were sampled on each channel. In addition, the bandpass filter outputs were half-wave rectified and integrated, and the outputs of the integrators were sampled. The Schmitt trigger data provided an index of the firing frequency of the larger spikes, whereas the integrated activity measured the voltage fluctuations of the entire record, including activity below the triggering thresholds. Schmitt trigger pulses were counted, and the integrator signals were digitized on each trial (CS presentation). Digital values were sampled every $10 \mathrm{msec}$. Sampling was performed for $1.0 \mathrm{sec}$, beginning $0.3 \mathrm{sec}$ before CS onset to $0.7 \mathrm{sec}$ after CS onset. The spike counts and integrator values provided an index of brief-latency multiunit responses to the CS + and CS-.

Collection of the brief-latency neuronal data used automatic and experimenter-controlled screening methods to ensure that the records did not contain noise related to spontaneous movements of the subject (Foster et al., 1980). For example, electronic noise detection eliminated trials accompanied by noise just before the CS or within $400 \mathrm{msec}$ of CS onset, and data analysis was limited to the $400 \mathrm{msec}$ period after CS onset, a time empirically established to precede behavioral response [conditioned response (CR)]-related noise (Foster et al., 1980).

Long-latency neuronal responses. In addition to the brief-latency data described above, methods were used in this study to obtain measures of neuronal activity beyond the $400 \mathrm{msec}$ epoch throughout the duration of the trial when the rabbits' CR-related movement could occur. Records containing discrete neuronal spikes were sampled at a rate of $25 \mathrm{kHz}$ using the Discovery Program of BrainWave Systems (now DataWave Technologies). The program stored to disk all spike waveforms that exceeded a preset voltage threshold, as well as the time of occurrence of each spike. Recording began $300 \mathrm{msec}$ before CS onset and continued throughout the trial until the subject made a spout contact response or until $5 \mathrm{sec}$ after CS onset in the case of trials with no response. The recording thresholds were set to record the largest spikes.

Standard spike sorting procedures (Payne et al., 1995) were used to exclude non-neuronal (noise) waveforms. Multiunit records containing spikes from three to five neurons throughout the full duration of the trials were analyzed. Studies in progress are examining the single-unit correlates of discriminative approach learning. Preliminary results have been presented in abstract form previously (Burhans et al., 2001).

Histology. After the completion of training, the animals were killed via an overdose of sodium pentobarbital, followed by transcardial perfusion with normal saline and $10 \%$ formalin. The brains were frozen and sectioned at $40 \mu \mathrm{m}$, and the sections were photographed while still wet (Fox and Eichman, 1959). After drying, the sections were stained with a metachromatic Nissl and myelin stain using formol thionin (Donovick, 1974). Photographs and stained sections were used to verify recording electrode locations. Lesion size was estimated by drawing damaged regions on photocopied images from the atlas of Girgis and Shih-Chang (1981). Nine sections were photocopied from 1.5 to $5.5 \mathrm{~mm}$ posterior to bregma. A grid with squares that subtended $0.25 \mathrm{~mm}^{2}$ of tissue was overlaid on the photocopied drawings. The number of squares covering damaged tissue was divided by the total number of squares covering the region of interest, yielding an estimate of the percentage of limbic thalamic tissue destroyed. Three rabbits were found to have $<50 \%$ of limbic thalamic tissue destroyed and were therefore excluded from the analyses. With these exclusions, a total of 13 control rabbits and 12 rabbits with lesions were retained for additional analysis. The mean damage score for the 12 rabbits with lesions was $90.17 \%$ of the total limbic thalamus (range of $69-100 \%$ ). The mean damage scores for individual nuclei were as follows: AD, $85.33 \%$; AV, $80.17 \%$; anteromedial, $83.92 \%$; and MD, 94.92\%. The smallest and largest lesions are depicted in Figure 1.

Because of the large size of the lesions, some damage occurred to nontargeted structures. These included the midline thalamic nuclei (four rabbits) and the stria medullaris and habenula (six rabbits). Separate 


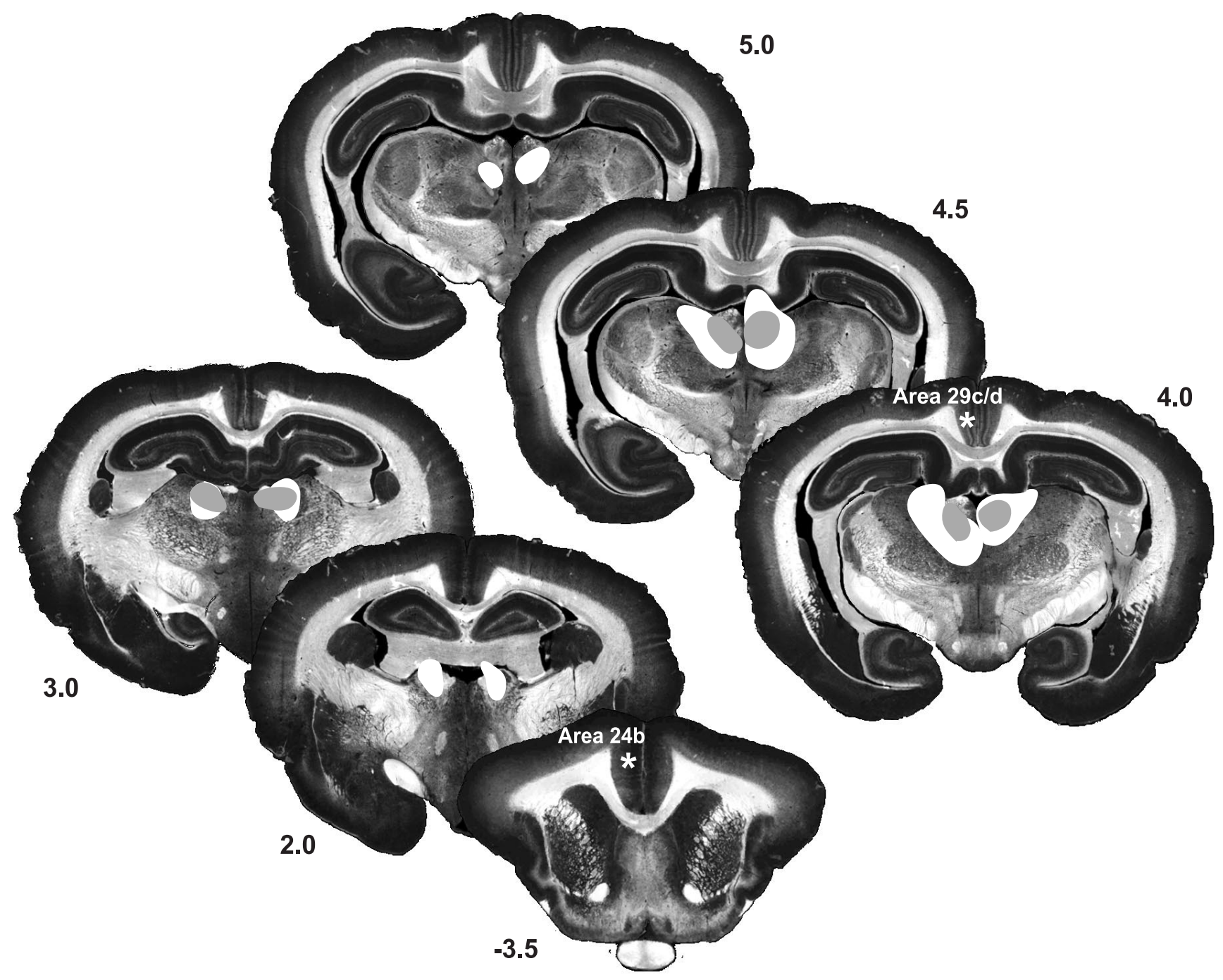

Figure 1. Coronal sections showing the smallest ( gray) and largest (white) lesions. Anterior cingulate cortical Area 24b and posterior cingulate cortical Area $29 \mathrm{c} / \mathrm{d}$ recording sites are indicated by asterisks. Coordinates are shown in millimeters from bregma.

ANOVA were computed for the number of sessions required for the attainment of the learning criterion in these two groups of rabbits. The data of each group were compared with the data of the remainder of the rabbits with lesions. These analyses did not yield significant betweengroup differences ( $p>0.44$ and $p>0.21$, respectively). Damage to the overlying hippocampal commissure and dorsal subiculum occurred in three rabbits. Because the sample of subjects with this damage was small, we did not feel that ANOVA would be appropriate. However, the hippocampal damage was minimal (see Fig. 1, large lesion), and the subjects that sustained it were among the fastest learners in the group with lesions. Thus, the hippocampal damage did not contribute to the significant learning deficit found in subjects with lesions (see Results). Moreover, hippocampal damage in the form of fornix lesions had no impact on discriminative approach learning (Gabriel et al., 2001).

Analysis of data. Because the rabbits took varying numbers of training sessions to attain the criterion, the data of seven training stages common to all subjects were analyzed. The stages included the first and last training sessions and five equally spaced sessions representing the second through the sixth training stages for each rabbit. Thus, the analysis included seven consecutive stages of training, each stage comprising one training session. The ordinal number of the training sessions (e.g., second session, third session, etc.) representing a given training stage varied among the rabbits. For example, the fourth stage (i.e., the midpoint of the seven stages) was represented by the fifth and the eighth training sessions for two rabbits that reached the criterion in 10 and 16 sessions, respec- tively. Thus, each training stage was designated in group data plots by the average of the session numbers comprising that stage (see Fig. 2). Five of the rabbits with lesions failed to attain the criterion. In these cases, training was discontinued after 45 sessions, and the data of these 45 sessions were divided into seven stages as described above.

For analysis of the behavioral data, the number of sessions required for attainment of the criterion and the percentage of trials in which a spout contact CR occurred were analyzed. The analysis of CR percentage at each training stage was a factorial, repeated-measures ANOVA computed using the $2 \mathrm{~V}$ program (BMDP Statistical Software). The factors used were as follows: group (control and lesion), stimulus (CS + and CS - ), and training stage (seven levels, as described above). Corrections of the $F$ tests attributable to violations of sphericity were performed as needed following the procedure of Huyhn and Feldt (1976). Factors yielding significant $F$ ratios were further analyzed using simple effect tests following procedures described by Winer (1962).

Analyses of the brief-latency neuronal data had the same form as the analyses of the CR percentage with an additional orthogonal factor, post-CS recording interval (40 consecutive $10 \mathrm{msec}$ intervals after CS onset). The training stage factor in the analysis of the neuronal data had eight levels rather than seven, because it included the neuronal activity recorded during the preliminary training session with noncontingent tone and water reward presentations. The preliminary training data were not included in analyses of the behavioral results because spout presentations did not follow CS presentations during preliminary training and 


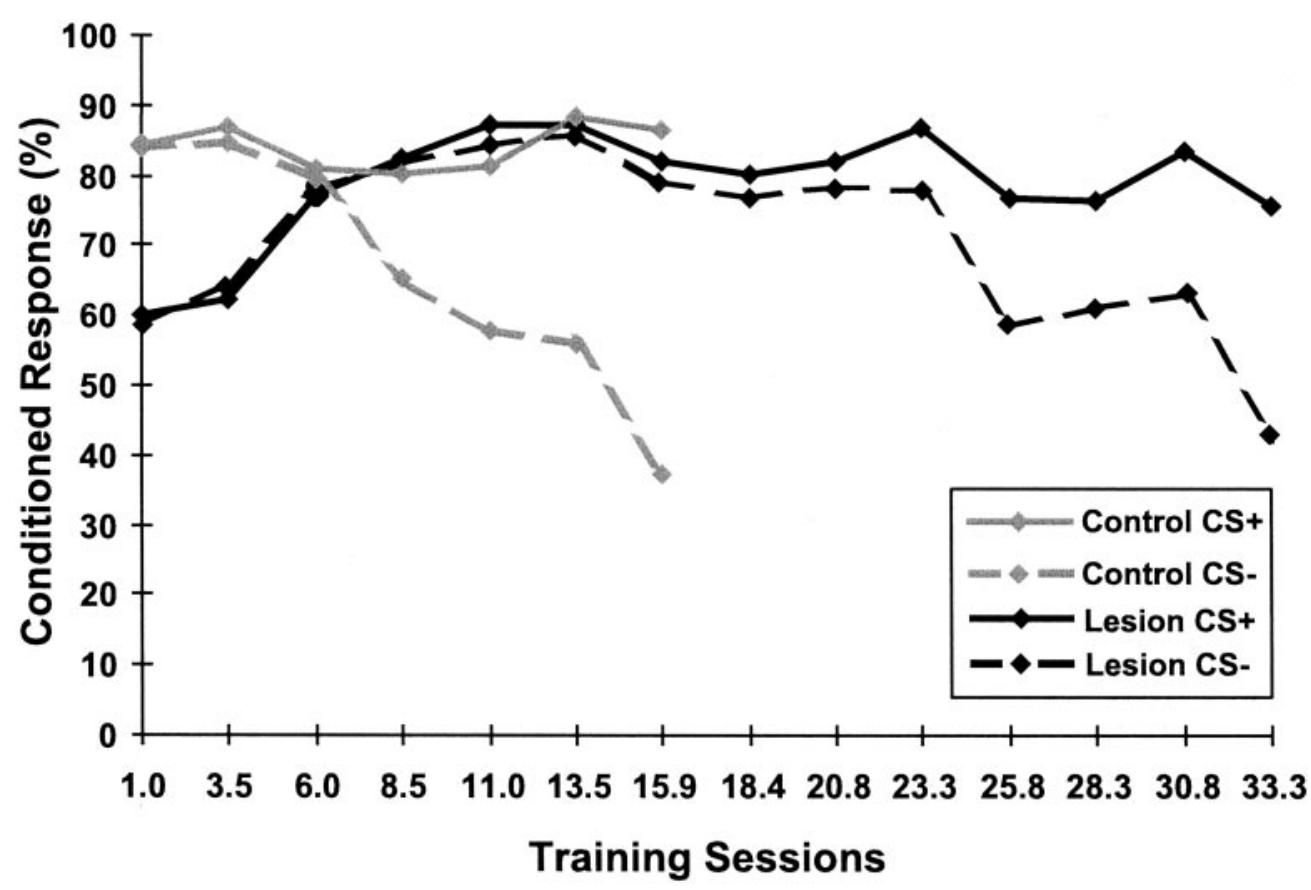

Figure 2. Percentage of spout contact responses made to the $\mathrm{CS}+$ (solid lines) and the CS- (dashed lines) by control rabbits (gray lines) and rabbits with lesions (black lines). Because the rabbits took varying numbers of training sessions to attain the criterion, the data of several training stages common to all subjects are shown. For control rabbits, the seven stages included the first and last training sessions and five equally spaced sessions representing the second through the sixth training stages for each rabbit. Rabbits with lesions required approximately twice the number of training sessions to attain criterion than controls. The abscissa labels indicate the average session numbers used for each training stage. For example, if the second training stage comprised sessions 4 , 5,6 , and 7 , the average of the sessions used to obtain data for the second training stage would be 5.5 . no spout contact CRs were possible. The data of anterior and posterior cingulate cortex were analyzed separately.

For the long-latency neuronal data, not all of the sessions provided usable multiunit records (i.e., records containing at least 2500 readily isolated spikes). The best two records were selected from among the first five training sessions to represent an early training stage. None of the rabbits exhibited significant discriminative behavior during these sessions. The records selected for the late training stage included the criterial session and a second postcriterial training session, which occurred within one or two sessions of the criterial session. Analysis of the long-latency neuronal data took the same form as the analysis of the brief-latency data, except that the post-CS interval factor had 43 levels (consecutive $100 \mathrm{msec}$ intervals after CS onset). The analyses showed that the long-latency responses in the anterior cingulate cortex were not significantly related to the training events. Therefore, only the posterior cingulate cortical long-latency data are presented.

\section{RESULTS}

\section{Behavior}

Behavior during acclimation and water consumption sessions

No differences between control rabbits and rabbits with lesions were found in the number of sessions required to attain the acclimation criterion before training $\left(F_{(1,23)}=0.096 ; p<0.76\right)$, the number of responses made during the final acclimation session $\left(F_{(1,20)}=1.487 ; p<0.24\right)$, or the amount of water consumed during the preliminary training sessions $\left(F_{(1,20)}=0.595 ; p<\right.$ $0.45)$. Water consumption of control rabbits and rabbits with lesions did not differ significantly during the ad libitum access period after the completion of training $\left(F_{(1,15)}=1.408 ; p<0.26\right)$.

\section{First stage of training}

Although there were no differences between groups before the initiation of training, rabbits with lesions approached the spout after its presentation less frequently than controls during the first session (stage) of training $(p<0.05)$. This reduced incidence of the approach response was nondiscriminative, i.e., it occurred equally on CS + and CS - trials (Fig. 2). This effect was indicated by simple effect tests after a significant interaction of the group and training stage factors $\left(F_{(6,138)}=3.36 ; p<0.01\right)$. It is suggested that the initial experiences of spout presentation followed by nonreward produced an emotional response that disrupted the approach response to the spout. Note that this interpretation is not in conflict with the finding (below) that the rabbits with lesions were severely retarded in learning to associate the CSwith nonreward. The latter impairment was an associative (discriminative) failure and, thus, need not have involved any lesionrelated change in emotionality.

\section{Sessions required to attain the criterion}

The rabbits with lesions exhibited a severe retardation of discriminative behavioral acquisition. The mean number of training sessions (33.3) required for attainment of the learning criterion by the rabbits with lesions was significantly greater than the mean number of sessions (15.9) required by controls $\left(F_{(1,23)}=16.44\right.$; $p<0.0001)$. Five of the 12 rabbits with lesions failed to reach the criterion within the 45 allotted sessions, and eight of the rabbits with lesions required $>30$ conditioning sessions. Only one of the 13 control rabbits required 30 training sessions to reach the criterion. The extent of damage to the limbic thalamus was significantly correlated with the number of sessions required to attain criterion $(n=12 ; r=+0.64 ; p<0.01)$.

\section{Performance during acquisition}

The percentage of CRs performed by rabbits with lesions and controls during the seven stages of training are plotted in Figure 2. The analysis of these data yielded a significant interaction of the group, stimulus, and training stage factors $\left(F_{(6,138)}=2.58 ; p<\right.$ $0.05)$. Simple effect tests showed that control rabbits developed significant discriminative responding (significantly more frequent responding on $\mathrm{CS}+$ trials than on $\mathrm{CS}-$ trials; $p<0.05$ ) after an average of 8.5 sessions. The rabbits with lesions did not exhibit significant discrimination until after an average of 25.8 conditioning sessions. Rabbits with lesions also responded to the CSsignificantly more often than controls throughout training, to and including the next-to-last conditioning session (after an average of 33.3 sessions; $p<0.05$ ). During the last conditioning session, rabbits with lesions responded to the $\mathrm{CS}-$ at a rate equivalent to 


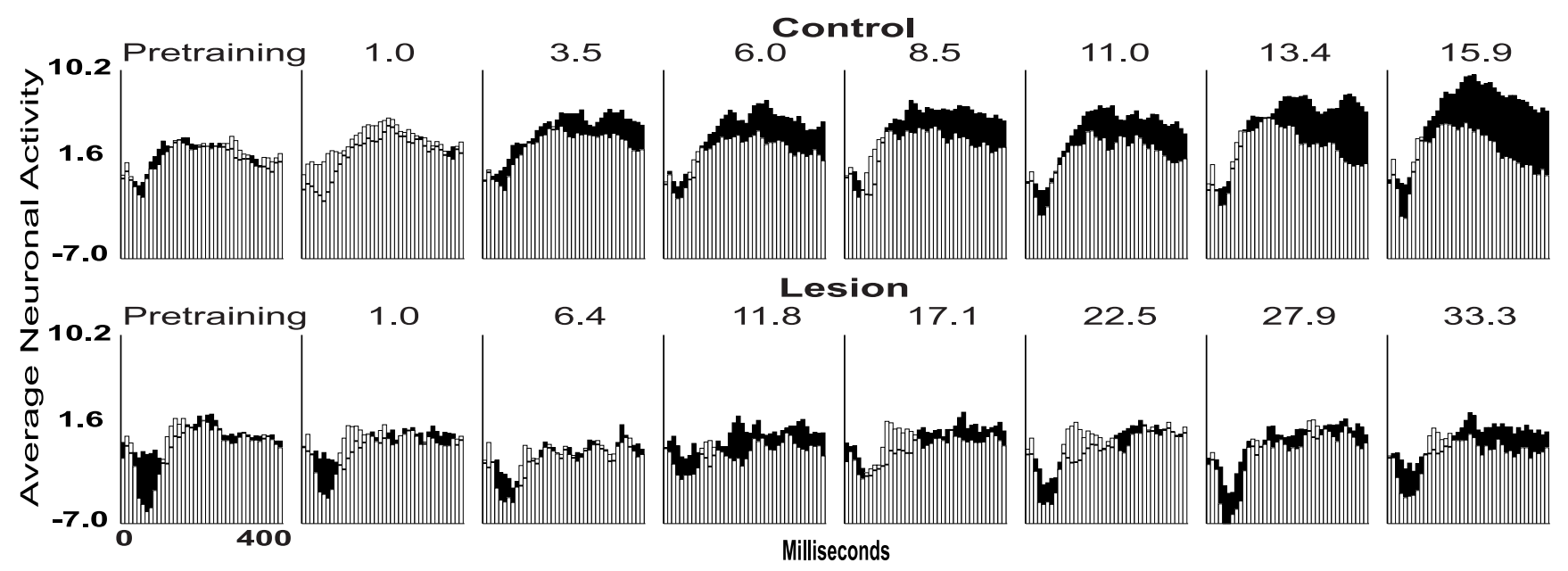

Figure 3. Average integrated unit activity in the posterior cingulate cortex of control rabbits (top row) and rabbits with lesions (bottom row) during preliminary training and seven equally spaced training stages. Each plot shows the average integrated unit activity, in the form of Z-scores normalized to pre-CS baseline, from CS onset for $400 \mathrm{msec}$ in $10 \mathrm{msec}$ intervals with the response to the CS + (black bars) and CS - (white bars). The numbers above each plot indicate the average of the ordinal numbers of the sessions that were averaged to obtain data for a given training stage. For example, if the second training stage comprised sessions $4,5,6$, and 7 , the average of the sessions used to obtain data for the second training stage would be 5.5 .

that of controls. Other than the aforementioned reduced overall responsiveness exhibited in the first training session by rabbits with lesions, no group differences were found with respect to responses to the $\mathrm{CS}+$, indicating that the lesion-induced deficit was primarily one of failure to withhold spout contact responses on CS - trials.

\section{Brief-latency neuronal activity in the posterior cingulate cortex}

The rabbits in the control group developed discriminative training-induced neuronal activity (greater neuronal firing in response to the $\mathrm{CS}+$ than to the $\mathrm{CS}-$ ) and excitatory traininginduced neuronal activity (greater firing in response to the CS+ during training compared with the firing to the CS+ during preliminary training) (Fig. 3, top row). A significant interaction of the group, training stage, and stimulus factors was found (spike frequency, $\left.F_{(7,105)}=2.78 ; p<0.05\right)$. The same interaction in the analysis of the integrated activity approached significance $\left(F_{(7,105)}=2.04 ; p<0.06\right)$. Control rabbits developed significant discriminative training-induced neuronal activity after an average of 6.0 conditioning sessions $(p<0.05)$. This discrimination persisted throughout training. Control rabbits first exhibited significant excitatory training-induced neuronal activity (spike frequency, $p<0.05$ ) on average after 3.5 conditioning sessions. This activity remained significant throughout the duration of training. None of these effects were significant in the rabbits with lesions (Fig. 3, bottom row).

\section{Long-latency neuronal activity in the posterior cingulate cortex}

Summary

Representative waveforms of the spikes contributing to the posterior cingulate cortical long-latency multiunit records are shown in Figure 4. The posterior cingulate cortical neurons of control rabbits developed long-latency training-induced neuronal responses (Fig. 5, top row). These responses took the form of anticipatory activity (increased firing beginning $\sim 2 \mathrm{sec}$ before the presentation of the drinking spout) and spout responses (a dramatic increase in firing after spout insertion). These responses were discriminative in that they were significantly greater on

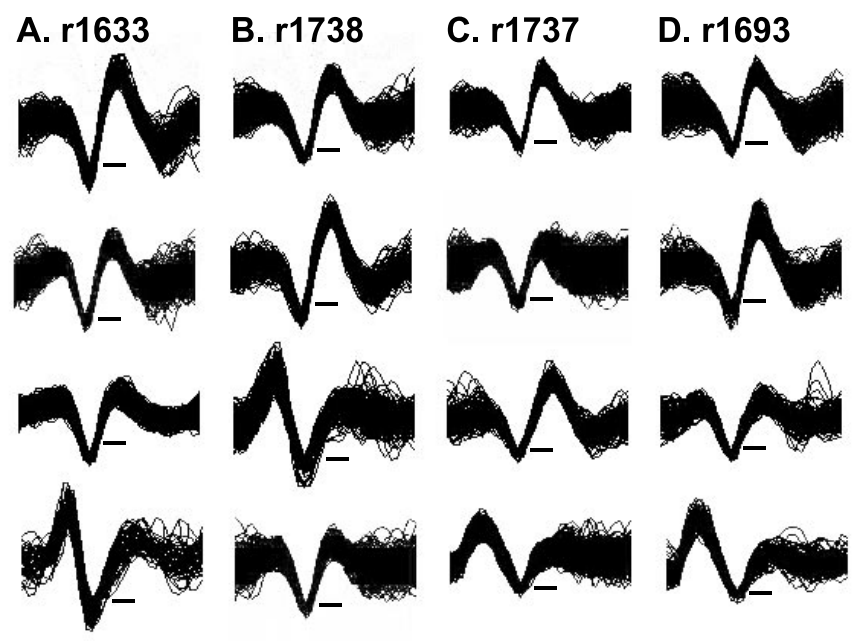

Figure 4. Spike overlays of the neurons contributing to the long-latency multiple-unit records of four representative rabbits. Two of the records were recorded in control rabbits $(A, B)$, and two were recorded in rabbits with lesions $(C, D)$. Spikes are shown for early $(A, C)$ and late $(B, D)$ training sessions. Recording thresholds are indicated by horizontal lines.

$\mathrm{CS}+$ trials than on CS - trials. This neuronal activity was significantly attenuated in rabbits with lesions (Fig. 5, bottom row).

\section{Details of the analysis}

The analysis yielded a significant three-way interaction of the training stage, stimulus, and group factors $\left(F_{(1,13)}=8.19 ; p<\right.$ $0.05)$. The four-way interaction of group, training stage, stimulus, and $100 \mathrm{msec}$ post-CS interval approached significance $\left(F_{(42,546)}\right.$ $=1.46 ; p<0.051)$. Individual comparisons were performed on the mean values of the four-way interaction. The intervals during which significant effects were found are given in Table 1.

\section{Neuronal responses to spout presentation}

The neuronal responses to the presentation of the spout were significantly attenuated in the rabbits with lesions during the early and late stages of training compared with the responses of controls $(p<0.05)$ (Fig. 5, 4000-4300 msec after CS onset). Control 


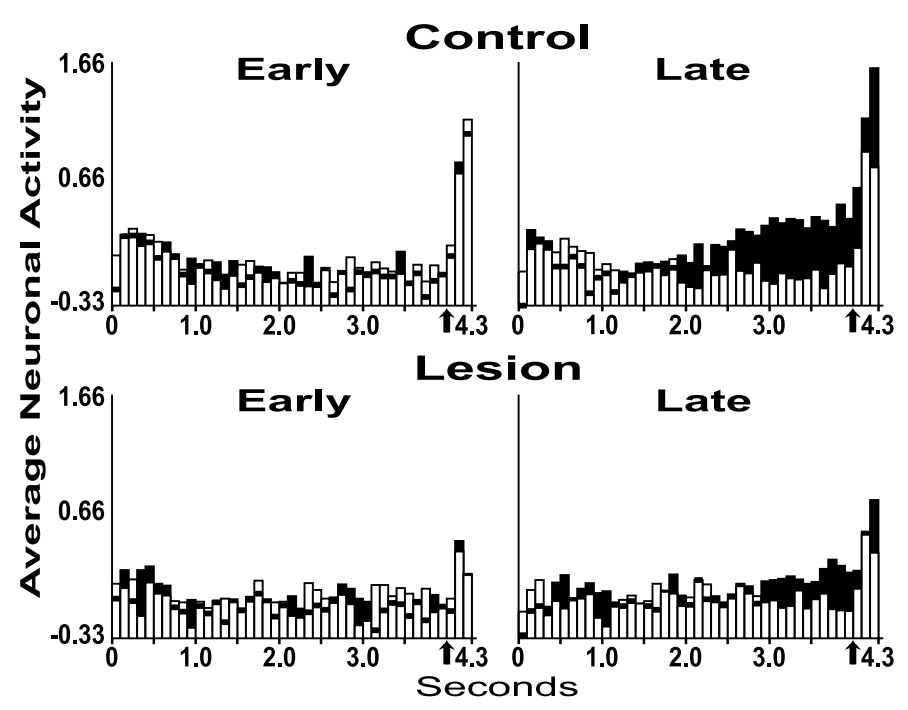

Figure 5. Average multiunit spike frequency in the posterior cingulate cortex of control rabbits (top row) and rabbits with lesions (bottom row) at the beginning of training (Early) and at the end of training (Late). Each plot shows the average number of spikes per trial, in the form of Z-scores normalized to pre-CS baseline, from CS onset for $4.3 \mathrm{sec}$ in $100 \mathrm{msec}$ intervals with the response to the CS+ (black bars) and CS - (white bars). CS onset occurred at $0 \mathrm{sec}$, and CS- offset occurred at $0.5 \mathrm{sec}$. Spout presentation occurred $4 \mathrm{sec}$ after CS onset and is indicated by an arrow.

rabbits exhibited a training-induced increase in the neuronal response to the spout during $\mathrm{CS}+$ trials and a training-induced decrease in the neuronal response to the spout during CS - trials (Fig. 5, top row). The neuronal responses on CS + trials during all three of the $100 \mathrm{msec}$ intervals after spout presentation were significantly increased late in training relative to the early training stage (all $p<0.05$ ). In contrast, the neuronal responses on CStrials were significantly reduced during the first $100 \mathrm{msec}$ period after spout presentation late in training compared with their magnitude during the early training stage $(p<0.05)$. Rabbits with lesions exhibited a training-induced increase in the neuronal response to the spout in only two of the $100 \mathrm{msec}$ intervals on $\mathrm{CS}+$ trials, and they exhibited no decline in responses to the spout on $\mathrm{CS}-$ trials. In both controls and rabbits with lesions, the neuronal responses to the spout were discriminative (significantly greater on $\mathrm{CS}+$ trials than on $\mathrm{CS}-$ trials; $p<0.05$ ).

\section{Anticipatory neuronal responses}

Control rabbits exhibited a training-induced increase in anticipatory activity during the recording period preceding spout presentation (Fig. 5, top row, 2100-4000 msec after CS onset). In control rabbits, the neuronal firing frequency in this interval was significantly greater in 15 of the $19100 \mathrm{msec}$ intervals during the late training stage, compared with the early training stage $(p<0.05)$. This training-induced increase in anticipatory activity occurred only on CS + trials. Consistent with this, the anticipatory activity was discriminative (significantly greater firing on $\mathrm{CS}+$ trials than on CS - trials). In controls, the neuronal firing on CS + trials was significantly greater than on CS - trials in 14 of the $19100 \mathrm{msec}$ intervals from the $2100-4000 \mathrm{msec}$ after CS onset (all $p<0.05$ ). The finding of associative neuronal activity in anticipation of spout presentation is consistent with results found in other laboratories (Hsieh et al., 1999; Sawamoto et al., 2000; Koyama et al., 2001). Anticipatory neuronal activity was significantly attenuated in rabbits with lesions. These rabbits exhibited significantly in-
Table 1. The intervals, in milliseconds after tone onset, during which significant effects were found in the long-latency neuronal activity of the posterior cingulate cortex (Fig. 5)

Comparison of control and lesion subjects (neuronal responses during CS + trials; LSD of 0.2879)

\begin{tabular}{|c|c|c|}
\hline Stage & Control $>$ lesion & Lesion $>$ control \\
\hline Early & $4100-4300$ & \\
\hline \multirow[t]{2}{*}{ Late } & 2800-2900 & \\
\hline & $4000-4300$ & \\
\hline
\end{tabular}

Training-induced changes in neuronal firing (comparison of early and late training stages; LSD of 0.2910)

\begin{tabular}{lll}
\hline & Control & Lesion \\
\hline Increase (CS+ trials) & $2100-2200$ & $3100-3200$ \\
& $2400-2500$ & $3700-3800$ \\
& $2600-3400$ & $4000-4100$ \\
& $3500-4300$ & $4200-4300$ \\
& Total of $1800 \mathrm{msec}$ & Total of $400 \mathrm{msec}$ \\
Decrease (CS - trials) & $4200-4300$ &
\end{tabular}

Discriminative neuronal responses (greater firing during CS + trials than during CS - trials; LSD of 0.2818)

\begin{tabular}{lll}
\hline Stage & Control & Lesion \\
\hline Early & & \\
Late & $2100-2200$ & $3700-4000$ \\
& $2600-2800$ & $4200-4300$ \\
& $2900-4100$ & \\
& $4200-4300$ & \\
& Total of $1600 \mathrm{msec}$ & Total of $400 \mathrm{msec}$ \\
\hline
\end{tabular}

Included are significant intervals for anticipatory neuronal activity $(2100-4000 \mathrm{msec}$ after CS onset) and neuronal responses to spout insertion (4000-4300 msec after CS onset). The spout was inserted $4000 \mathrm{msec}$ after CS onset. Least significant difference (LSD) values are given for each comparison.

creased firing from the early to the late training stage on CS+ trials in just two of the $19100 \mathrm{msec}$ intervals preceding spout presentation, and the neuronal responses during $\mathrm{CS}+$ trials were significantly greater than the responses during $\mathrm{CS}-$ trials in only three of the $19100 \mathrm{msec}$ intervals in rabbits with lesions $(p<$ $0.05)$.

\section{Individual long-latency neuronal records}

The findings described above were readily observable in the single-session neuronal records from individual rabbits (Fig. 6). The records shown are representative of the full data set, indicating the development of discriminative spout responses and anticipatory responses in controls and attenuation of these effects in rabbits with lesions.

\section{Brief-latency neuronal activity in the anterior cingulate cortex}

In contrast to previous studies of discriminative avoidance learning (for review, see Gabriel, 1993), control rabbits did not develop significant discriminative neuronal activity in the anterior cingulate cortex (interaction of the stage, stimulus, and group factors: spike frequency, $F_{(7,147)}=0.34, p<0.95$; integrated activity, $\left.F_{(7,147)}=0.62, p<0.73\right)$ (Fig. 7). The rabbits with lesions also did not develop discriminative neuronal activity.

\section{DISCUSSION}

\section{Summary of findings and conclusions}

Discriminative approach learning was severely retarded and posterior cingulate cortical training-induced discriminative neuronal 


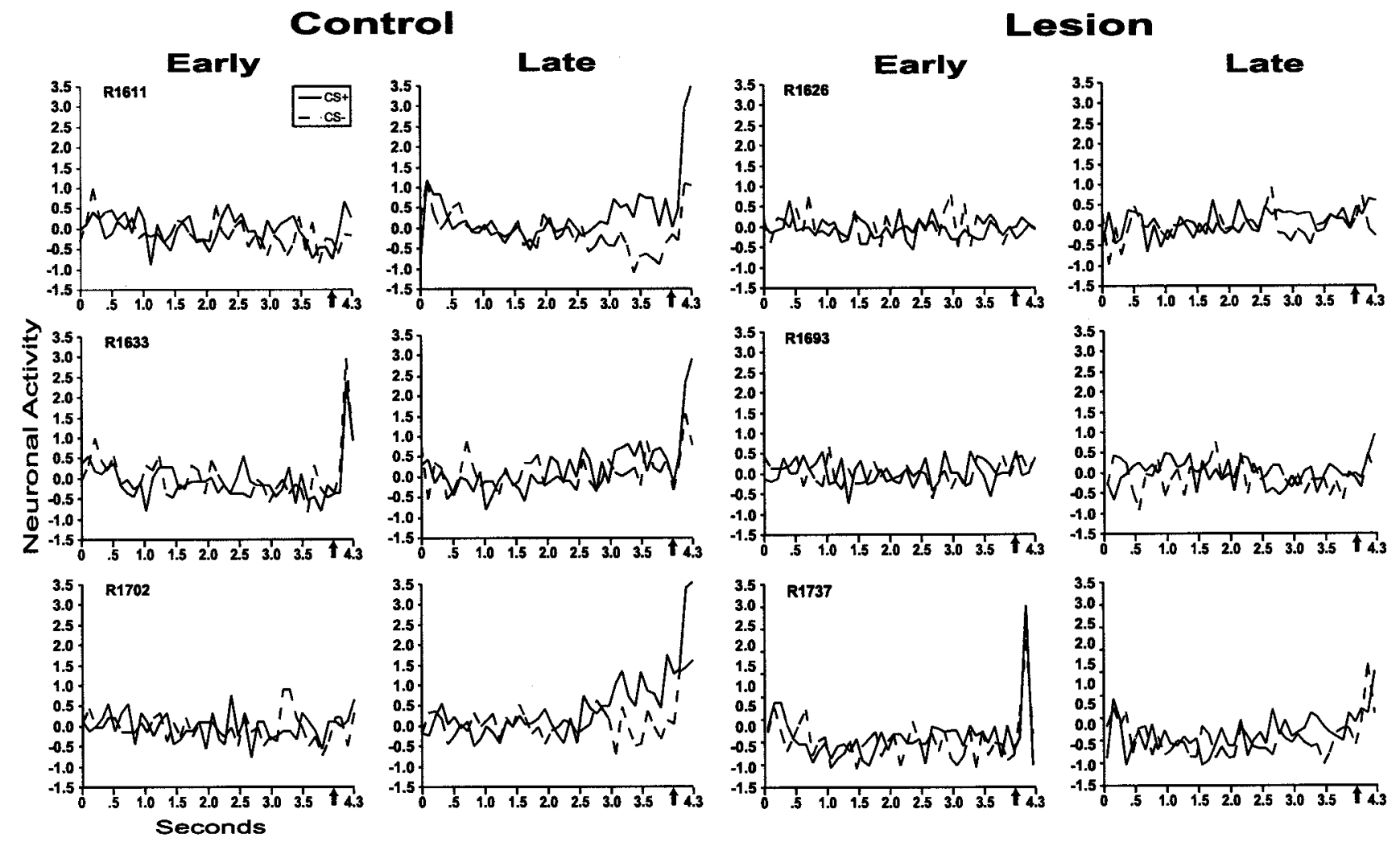

Figure 6. Representative individual posterior cingulate cortical multiunit records from three control rabbits and three rabbits with lesions. Data are shown for early and late training sessions for each rabbit. Each plot shows the spike frequency, in the form of Z-scores normalized to pre-CS baseline, from CS onset to $4.3 \mathrm{sec}$ after CS onset, in $100 \mathrm{msec}$ intervals. The solid and dashed lines show the responses to the CS+ and CS-, respectively. CS onset occurred at $0 \mathrm{sec}$, and CS offset occurred at $0.5 \mathrm{sec}$. Spout presentation (arrow) occurred $4 \mathrm{sec}$ after CS onset.

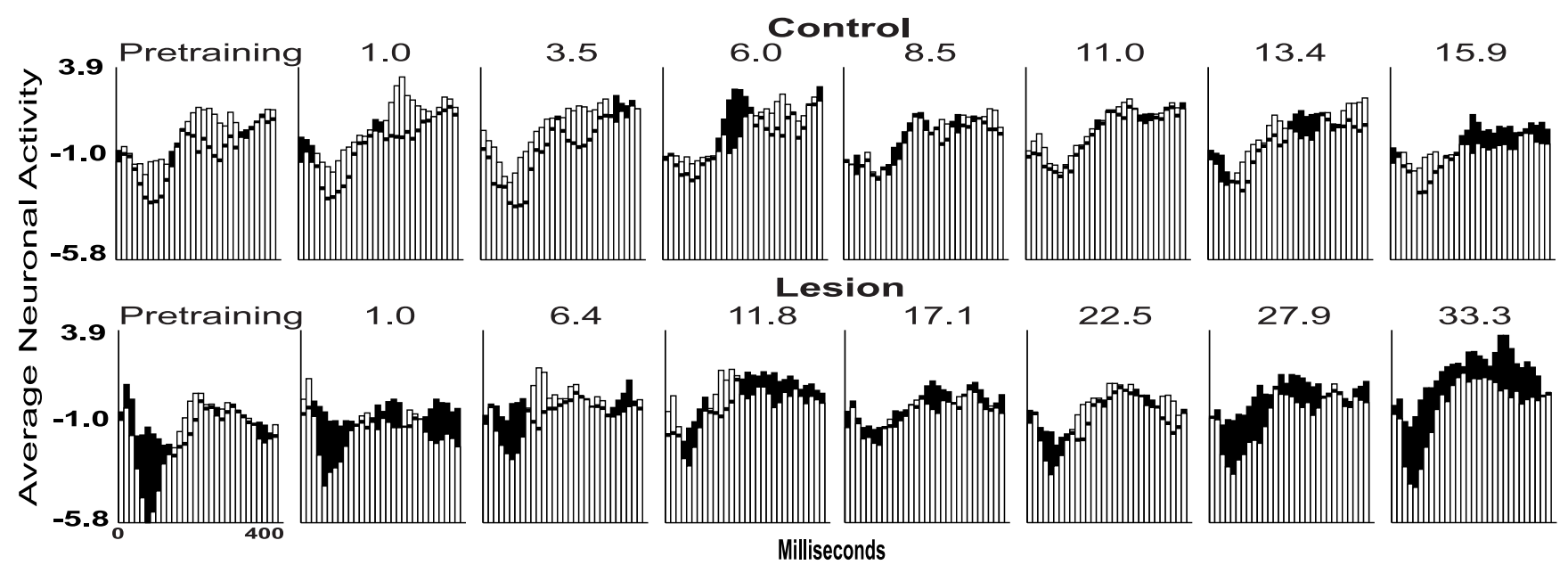

Figure 7. Average integrated unit activity in the anterior cingulate cortex of control rabbits (top row) and rabbits with lesions (bottom row) during preliminary training and seven equally spaced training stages. Each plot shows the average integrated unit activity, in the form of Z-scores normalized to pre-CS baseline, from CS onset for $400 \mathrm{msec}$ in $10 \mathrm{msec}$ intervals with the response to the CS+ (black bars) and CS- (white bars). Numbers above each plot indicate the average number of conditioning sessions represented by that stage. For example, if the second training stage comprised sessions $4,5,6$, and 7 , the average of the sessions used to obtain data for the second training stage would be 5.5.

activity was severely attenuated in rabbits with limbic thalamic lesions.

Because the rabbits learned to approach drinking spouts before training, they did not learn this response during training. From the outset of training, the approach response was made directly to spout presentation, with which the $\mathrm{CS}+$ was redundant. As a result, discriminative approach learning was expressed exclusively as learning to omit the highly overlearned approach response when spout presentations were preceded by the CS - and no reward was forthcoming. The lesions disturbed this omission learning. In contrast, cingulothalamic lesions in previous studies severely impaired the learning of active locomotor avoidance 
responses to a $\mathrm{CS}+$. Therefore, cue processing suffers in subjects with cingulothalamic lesions generally, whether they are required to perform active responses on cue (as during discriminative avoidance learning) or to omit responses on cue (as in the discriminative approach task).

In addition to the impairment of omission learning, the data indicated for the first time a direct involvement of the cingulothalamic circuitry in associative processes of appetitive instrumental learning. This is shown by the slowly acquired but robust associative coding of the reward-predictive CS + in the posterior cingulate cortex and by the absence of this coding in the rabbits with lesions. As noted, the rabbits with lesions approached the spout on virtually every $\mathrm{CS}+$ trial. These responses were very likely mediated by neuronal coding of the drinking spout itself, a coding consolidated to noncingulothalamic areas during the extensive previous experience with spouts. That such consolidation occurs during overtraining has been indicated previously (Hart et al., 1997). It is likely, however, that the discriminative approach responses exhibited after eight training sessions by the control rabbits were dependent on the TIA in the posterior cingulate cortex.

In summary, past and present data support cingulothalamic involvement in the mediation of the following: (1) associations between a CS+ and an aversive (foot shock) reinforcer for acquisition of an active locomotory avoidance CR; (2) appetitively based $\mathrm{CS}+$ and reward associations subserving a head extension CR, and; (3) CS - and nonreward associations subserving CR omission. These results thus add substantially to knowledge of the range of task and behavioral response characteristics to which cingulothalamic processing is relevant.

\section{Neural coding of response omission}

Was the lesion-related impairment of response omission on CStrials supported in controls by TIA increments in response to the $\mathrm{CS}-$ ? Increments of the multiunit response to the $\mathrm{CS}-$ were not found in the anterior or posterior cingulate cortex. As noted, incremental coding occurred in response to the $\mathrm{CS}+$ in the posterior cingulate cortex, and associative coding of the spout was also incremented when spout presentation was preceded by the $\mathrm{CS}+$. However, neural responses to the spout diminished with training when spout presentation was preceded by the CS-. The combination of incremental coding on CS + trials and decremental coding on $\mathrm{CS}-$ trials is sufficient to account for the discriminative learning without recourse to incremental coding of the $\mathrm{CS}-$. Nevertheless, incremental coding of the CS- may have occurred, possibly in areas other than the posterior cingulate cortex. Preliminary analyses suggest that single cells exhibit incremental coding of the $\mathrm{CS}-$ in anterior cingulate cortex (Burhans et al., 2001). Indeed, even during avoidance learning a small proportion $(10 \%)$ of single cells throughout the cingulothalamic circuit exhibited CS - specific firing in trained rabbits, and $40 \%$ of responsive cells in the MD nucleus showed this effect (Kubota et al., 1996). Thus, we cannot exclude the possibility that the impaired approach learning in rabbits with lesions may have been attributable in part to interference with incremental coding of the $\mathrm{CS}-$.

\section{The cingulothalamic circuit and associative attention}

The foregoing observations are in keeping with a long-standing hypothesis that cingulothalamic neurons encode the associative significance of task-relevant stimuli. This encoding is expressed by the TIA that develops in response to the $\mathrm{CS}+$ and $\mathrm{CS}-$
(Gabriel et al., 1980). A recent elaboration holds that the discriminative TIA subserves associative attention and retrieval of learned responses (Gabriel and Talk, 2001).

The idea of a cingulothalamic role in attention is based on multiple findings, including the TIA itself, the remarkable enhancement of TIA when nonsalient CSs are used (Sparenborg and Gabriel, 1990; Gabriel and Taylor, 1998; Harvey et al., 2000), and the results of brain imaging studies with human subjects (Pardo et al., 1990; Bench, 1993; Marshall et al., 1997; Petersen et al., 1998; Posner and DiGirolamo, 1998; Mesulam et al., 2001)

\section{Rapid and slow coding}

No significant TIA was found in the anterior cingulate cortex in this study, and minimal, late TIA was found in a previous study of discriminative approach learning (Freeman et al., 1996). These results contrast with studies of discriminative avoidance learning, wherein the multiunit records in anterior cingulate cortex exhibited robust TIA in the very early stages of acquisition (for review, see Gabriel, 1993). This rapid TIA is dependent on the integrity of the amygdala (Poremba and Gabriel, 1997). More recently, rapid, early TIA was found to develop during discriminative avoidance learning in the basolateral nucleus of the amygdala and the medial division of the medial geniculate nucleus, as well as in the anterior cingulate cortex (Duvel et al., 2001). Auditory cortical lesions abolished the rapid TIA in all of these areas, and rapid behavioral learning, while leaving slower neuronal coding and behavioral learning intact. These areas thus form a circuit that is essential for rapid discriminative avoidance learning.

The involvement of this rapid circuit in avoidance learning is consistent with the possibility (above) that incremental CScoding reinforced by aversive nonreward may also be mediated by processes of the anterior cingulate cortex and related areas. Note that the coding of the CS- subserves the discriminative learning of CR omission, and failure of this coding promotes errors of commission as found here in the rabbits with lesions. These considerations bring the present data into register with the growing body of evidence indicating a role of the anterior cingulate cortex in processing of errors (Gemba et al., 1986; Gehring et al., 1993; Falkenstein et al., 1995; Luu et al., 2000).

In contrast to the rapid coding circuit, discriminative approach learning and coding of associative attention in posterior cingulate cortex are slowly acquired. The amygdala is not involved in this learning (Smith et al., 2001), although the amygdala is needed for a more accelerated posterior cingulate coding during discriminative avoidance learning (Poremba and Gabriel, 1997). These findings are in accord with the hypothesis (Gabriel, 1993) that the posterior cingulate cortex and related circuitry mediate relatively gradual coding of consistent, repeating stimulus-reinforcement relationships. Coding in this circuit may also be driven by off-line rehearsal and rehearsal-like processes that are tantamount to event repetition (Freeman and Gabriel, 1999; Sutherland and McNaughton, 2000). As mentioned, avoidance trials are coded in the posterior cingulate cortex more rapidly than approach trials. However, both motivationally urgent and less urgent coding occurs in this circuit in a relatively gradual manner compared with the rapid coding circuit.

\section{Rapid and slow neural coding and memory: filtration of experience?}

It is intriguing to consider the functional significance of the rapid and slow coding circuits. Our proposal begins with the notion that the two circuits mediate different specializations of the memory 
system (Gabriel and Talk, 2001; Gabriel et al., 2002). We suggest that the two circuits implement an experience-filtering process. Rapid coding ensures that details of immediate, novel experience, and especially highly aversive novel experience such as trials of avoidance conditioning, are stored for a relatively brief time, measured in hours. In humans, processes of the anterior cingulate and prefrontal cortex, and the related MD thalamic nucleus, mediate this coding. It allows, for example, recall of all of the events of the day at the end of the day. However, because it is specialized for the coding of novel events, such coding will displace previously formed codes in this circuit. Repetitive events will be stored by this circuit on their initial occurrences, but repetition will not strengthen the stored code. Thus, the circuit is not well organized for enduring storage of information. For example, without rehearsal, one is not able, typically, to recall all events on a particular day of the previous week. Generally, much information stored via the rapid coding mechanism proves to be of no significance, it is not rehearsed, and it is lost. The loss of irrelevant data are an important function of the experiencefiltering process.

The more gradual and enduring coding that occurs in the posterior cingulate cortical circuit is, like the rapid coding circuit, driven by single inputs that are highly significant (such as highly aversive or emotional experiences). However, these events are stored not because they are novel; rather, they are stored because they are rehearsed. Less significant events (such as trials of discriminative approach learning) are coded in the slow circuit because they are repeated frequently. These "admission requirements" represent a barrier that "filters out" the coding of events that are neither important, rehearsed, nor repeated, thus enabling only significant experiences to achieve a consolidated status in memory.

\section{REFERENCES}

Aggleton JP, Brown MW (1999) Episodic memory, amnesia, and the hippocampal-thalamic axis. Behav Brain Sci 22:425-444.

Bench CJ (1993) Investigations of the functional anatomy of attention using the stroop test. Neuropsychologia 31:907-922.

Beracochea DJ, Jaffard R, Jarrard LE (1989) Effects of anterior or dorsomedial thalamic ibotenic lesions on learning and memory in rats. Behav Neural Biol 51:364-376.

Burhans L, Barnes T, Haider B, Smith DM, Gabriel M (2001) Cingulate cortical multiple and single unit correlates of discriminative approach learning. Soc Neurosci Abstr 27:537.14.

Bussey TJ, Muir JL, Everitt BJ, Robbins TW (1996) Dissociable effects of anterior and posterior cingulate cortex lesions on the acquisition of a conditional visual discrimination: facilitation of early learning vs. impairment of late learning. Behav Brain Res 82:45-56.

Bussey TJ, Muir JL, Everitt BJ, Robbins TW (1997) Triple dissociation of anterior cingulate, posterior cingulate, and medial frontal cortices on visual discrimination tasks using a touchscreen testing procedure for the rat. Behav Neurosci 111:920-936.

Donovick PJ (1974) A metachromatic stain for neural tissue. Stain Technol 49:49-51.

Duvel A, Smith DM, Talk A, Gabriel M (2001) Medial geniculate, amygdalar and cingulate cortical training-induced neuronal activity during discriminative avoidance learning in rabbits with auditory cortical lesions. J Neurosci 21:3271-3281.

Falkenstein M, Hohnsbein J, Hoormann J (1995) Event-related potential correlates of errors in reaction tasks. Electroencephalogr Clin Neurophysiol Suppl 44:287-296.

Foster K, Orona E, Lambert RW, Gabriel M (1980) Early and late acquisition of discriminative neuronal activity during differential conditioning in rabbits: specificity within the laminae of cingulate cortex and the anteroventral thalamus. J Comp Physiol Psychol 94:1069-1086.

Fox CA, Eichman J (1959) A rapid method for locating intracerebral electrode tracks. Stain Technol 34:39-42.

Freeman Jr JH, Gabriel M (1999) Changes of cingulothalamic topographic excitation patterns and avoidance response incubation over time following initial discriminative conditioning in rabbits. Neurobiol Learn Mem 72:259-272.

Freeman Jr JH, Cuppernell C, Flannery K, Gabriel M (1996) Limbic thalamic, cingulate cortical and hippocampal neuronal correlates of discriminative approach learning in rabbits. Behav Brain Res 80:123-136.

Gabriel M (1993) Discriminative avoidance learning: a model system. In: Neurobiology of cingulate cortex and limbic thalamus (Vogt BA, Gabriel M, eds), pp 478-523. Boston: Birkhauser.

Gabriel M, Talk A (2001) A tale of two paradigms: lessons learned from parallel studies of discriminative instrumental learning and classical eyeblink conditioning. In: Model systems and the neurobiology of associative learning (Steinmetz JA, Gluck M, Solomon PR, eds), pp 149-185. Mahwah, NJ: Erlbaum.

Gabriel M, Taylor C (1998) Prenatal exposure to cocaine impairs neuronal coding of attention and discriminative learning. Ann NY Acad Sci 846:194-212.

Gabriel M, Foster K, Orona E, Saltwick SE, Stanton M (1980) Neuronal activity of cingulate cortex, anteroventral thalamus and hippocampal formation in discriminative conditioning: encoding and extraction of the significance of conditional stimuli. In: Progress in physiological psychology and psychobiology (Sprague J, Epstein AN, eds), pp 126223. New York: Academic.

Gabriel M, Sparenborg S, Kubota Y (1989) Anterior and medial thalamic lesions, discriminative avoidance learning, and cingulate cortical neuronal activity in rabbits. Exp Brain Res 76:441-457.

Gabriel M, Cuppernell C, Shenker JI, Kubota Y, Henzi V, Swanson D (1995) Mamillothalamic tract transection blocks anterior thalamic training-induced neuronal plasticity and impairs discriminative offidance behavior in rabbits. J Neurosci 15:1437-1445.

Gabriel M, Smith DM, Wakeman D (2001) Fornix lesions and concurrent discriminative approach and avoidance learning. Soc Neurosci Abstr 27:537.17.

Gabriel M, Burhans L, Talk A, Scalf P (2002) The cingulate cortex. In: Encyclopedia of the human brain (Ramachandran VS, ed), pp 775-791. New York: Academic.

Gehring WJ, Gross B, Coles MGH, Meyer DE, Donchin E (1993) A neural system for error detection and compensation. Psychol Sci 4:385-390.

Gemba H, Sasaki K, Brooks VB (1986) "Error" potentials in limbic cortex (anterior cingulate area 24) of monkeys during motor learning. Neurosci Lett 70:223-227.

Girgis M, Shih-Chang W (1981) A new stereotaxic atlas of the rabbit brain. St. Louis: Green.

Hart M, Poremba A, Gabriel M (1997) The nomadic engram: overtraining eliminates the impairment of discriminative avoidance behavior produced by limbic thalamic lesions. Behav Brain Res 82:169-177.

Harvey JA, Romano AJ, Gabriel M, Simansky KJ, Du W, Aloyo VJ, Friedman E (2000) Effects of prenatal exposure to cocaine on the developing brain: anatomical, chemical, physiological and behavioral consequences. Neurotoxicity Res 3:117-143.

Hsieh JC, Stone-Elander S, Ingvar M (1999) Anticipatory coding of pain expressed in the human anterior cingulate cortex: a positron emission tomography study. Neurosci Lett 262:61-64.

Huyhn H, Feldt LS (1976) Estimation of the box correction for degrees of freedom from sample data in randomized block and split-plot factorial designs. J Edu Stat 1:69-82.

Isserhoff A, Rosvold TW, Galkin TW, Goldman-Rakic PS (1982) Spatial memory impairments following damage to the mediodoral nucleus of the thalamus in rhesus monkeys. Brain Res 232:97-113.

Koyama T, Kato K, Tanaka YZ, Mikami A (2001) Anterior cingulate activity during pain-avoidance and reward tasks in monkeys. Neurosci Res 39:421-430.

Kubota Y, Wolske M, Poremba A, Kang E, Gabriel M (1996) Stimulusrelated and movement-related single-unit activity in rabbit cingulate cortex and limbic thalamus during performance of discriminative avoidance behavior. Brain Res 721:22-38.

Luu P, Flaisch T, Tucker DM (2000) Medial frontal cortex in action monitoring. J Neurosci 20:464-469.

Markowitsch HJ (1982) Thalamic medial dorsal nucleus and memory; a critical evaluation of studies in animals and man. Neurosci Biobehav 6:351-380.

Marshall RS, Lazar RM, Van Heertum RL, Esser PD, Perera GM, Mohr JP (1997) Changes in regional cerebral blood flow related to line bisection discrimination and visual attention using hmpao-spect. NeuroImage 6:139-144.

Mesulam MM, Nobre AC, Kim YH, Parrish TB, Gitelman DR (2001) Heterogeneity of cingulate contributions to spatial attention. NeuroImage 13:1065-1072.

Pardo JV, Pardo PJ, Janer KW, Raichle ME (1990) The anterior cingulate cortex mediates processing selection in the stroop attentional conflict paradigm. Proc Natl Acad Sci USA 87:256-259.

Parker A, Gaffan D (1997). The effect of anterior thalamic and cingulate cortex lesions on object- in-place memory in monkeys. Neuropsychologia 35:1093-1102.

Payne JR, Quinn SJ, Wolske M, Gabriel M, Nelson ME (1995) An information system for neuronal pattern analysis. Soc Neurosci Abstr 21:944. 
Petersen SE, van Mier H, Fiez JA, Raichle ME (1998) The effects of practice on the functional anatomy of task performance. Proc Natl Acad Sci USA 95:853-860.

Poremba A, Gabriel M (1997) Amygdalar lesions block discriminative avoidance learning and cingulothalamic training-induced neuronal plasticity in rabbits. J Neurosci 17:5237-5244.

Posner MI, DiGirolamo GJ (1998) Executive attention: conflict, target detection, and cognitive control. In: The attentive brain (Parasuraman $\mathrm{R}$, ed), pp 401-423. Cambridge, MA: MIT.

Sawamoto N, Honda M, Okada T, Hanakawa T, Kanda M, Fukuyama H, Konishi J, Shibasaki H (2000) Expectation of pain enhances responses to nonpainful somatosensory stimulation in the anterior cingulate cortex and parietal operculum/posterior insula: an event-related functional magnetic resonance imaging study. J Neurosci 20:7438-7445.

Smith DM, Monteverde J, Schwartz E, Freeman Jr JH, Gabriel M (2001) Lesions in the central nucleus of the amygdala: discriminative avoid- ance learning, discriminative approach learning, and cingulothalamic training-induced neuronal activity. Neurobiol Learn Mem 76:403-425.

Sparenborg S, Gabriel M (1990) Neuronal encoding of conditional stimulus duration in the cingulate cortex and the limbic thalamus of rabbits. Behav Neurosci 104:919-933.

Squire LR, Amaral DG, Zola-Morgan S, Kritchevsky M, Press G (1989) Description of brain injury in the amnesic patient N.A. based on magnetic resonance imaging. Exp Neurol 105:23-35.

Sutherland GR, McNaughton B (2000) Memory trace reactivation in hippocampal and neocortical neuronal ensembles. Curr Opin Neurobiol 10:180-186.

Victor M, Adams RD, Collins GH (1971) The Wernicke-Korsakoff syndrome and related neurologic disorders due to alcoholism and malnutrition, Ed 2. Philadelphia: Davis.

Winer BJ (1962) Statistical principles in experimental design, pp 298374. New York: McGraw Hill. 